\title{
Acoustic Emission Precursors of M6.0 2004 Parkfield and M7.0 1989 Loma Prieta Earthquakes
}

\author{
Valeri Korneev \\ Lawrence Berkeley National Laboratory, Berkeley, California \\ VAKorneev@lbl.gov
}

\begin{abstract}
Two recent strike-slip earthquakes on the San Andreas Fault (SAF) in California, the M6.0 2004 Parkfield and M7.0 1989 Loma Prieta events, revealed peaks in the acoustic emission (AE) activity in the surrounding crust several months prior to the main events. Earthquakes directly within the SAF zone were intentionally excluded from the analysis. The observed increase in $A E$ is assumed to be a signature of the increasing stress level in the surrounding crust, while the peak and subsequent decrease in AE starting several months prior to the main events is attributed to damage-induced softening processes as discussed herein. Further, distinctive zones of low seismic activity surrounding the epicentral regions in the pre-event time period are present for the two studied events. Both $A E$ increases in the crust surrounding a potential future event and the development of a low-seismicity epicentral zone can be regarded as promising precursory information that could help signal the arrival of large earthquakes.
\end{abstract}

\section{Introduction}

The town of Parkfield, located on the SAF in central California, has been the site of intensive, multidisciplinary earthquake studies since the 1970s. Moderate-sized earthquakes of about magnitude 6 have occurred on the Parkfield section of the SAF at fairly regular intervals -in 1857, 1881, 1901, 1922, 1934, and 1966. The 1857 event was a foreshock of the great Fort Tejon M8.3 earthquake, which ruptured the fault from Parkfield to the southeast for over $290 \mathrm{~km}$. Possibility that another moderate-sized Parkfield earthquakes might occur as a foreshock to another Fort Tejon type event remains high. The goal of research in the Parkfield area has been to observe the fault and surrounding crust at close range and at high resolution before, during, and after a characteristic M6 earthquake, so as to better understand the earthquake process and to provide a scientific basis for earthquake prediction and hazard assessment. Recognizing this hazard, and the regular periodicity of recurring events near Parkfield, the U.S. 
Geological Survey (USGS) and the State of California began a comprehensive, longterm Parkfield Earthquake Prediction Project in 1985 (1). More than 10,000 earthquakes have been recorded since 1970 in the magnitude range $0<M<5$. The long anticipated M6.0 event finally occurred September 28, 2004. One month later, a joint team of seismologists issued a preliminary report (2) indicating that no immediate precursory phenomena were observed. At a special session of the American Geophysical Union 2004 Fall Meeting in San Francisco dedicated exclusively to the M6.0 2004 Parkfield event, there were no reports of any promising precursory signals except for some of the results as presented below.

There is currently not much optimism in the scientific community about the possibility of earthquake prediction (3-5). Quotes from recent discussions in Nature (6) include: "...we do not have a method for making short-term predictions"; "...there is a bleak future for individual earthquake prediction"; and "...there is no prospect of deterministic earthquake prediction in the foreseeable future". It is not an intention of this paper to give an overview of current earthquake prediction methods. The author simply notes that most methods [e.g., (7)] seek changes in coefficients of the Gutenberg-Richter law $\log \mathrm{N}=\mathrm{a}-\mathrm{bM}$ that relates the number $\mathrm{N}$ of earthquakes greater than magnitude $\mathrm{M}$ in some region to the magnitude. This law reflects a behavior of seismicity observed during a sufficiently long time needed to collect reliable statistics for a wide range of magnitudes. Accordingly, using this law as a basis for prediction approach has several weaknesses. First, the relatively rare occurrence of large magnitude events means there is great uncertainty in predicting the probability of a large event. Second, applications of this law provide no information concerning the location of an event within a catalogued region. Last, current earthquake generating models give little or no direct dependence between changes in the Gutenberg-Richter law coefficients ( $a$ and $b$ ) and characteristic earthquake occurrence. Taking into account the large time intervals between catastrophic events, which typically take place every 100-200 years, even moderate uncertainty in prediction makes it unrealistic to use such statistics for disaster related warnings. Practically applicable prediction methods need to be based on causal approaches.

In this paper a selective seismicity analysis is used which is a main conclusion from data analysis for Vibroseis monitoring experiment, where seismic waves repeatedly 
illuminated the epicentral region of the expected M6 event at Parkfield from June 1987 until November 1996. Data collected by the borehole network were examined for evidence of changes associated with the nucleation process of the anticipated M6 earthquake at Parkfield $(8,9,10)$. These investigations reported significant traveltime changes for paths crossing the fault zone in the locked SE part of SAF, while for the NW (creeping) part of the SAF no changes were observed. This result suggests that seismicity of the creeping part of SAF contains no or little information about stress accumulation in SAF, where weak fault steadily releases small stress changes and seismicity of this zone mostly represents stationary random process. Therefore, all the events with hypocenters within the active fault zone are excluded from the results shown in this paper. The transition zone between locked and creeping parts of SAF is a northwesterly dipping structure at approximately 45 degrees of extending at about $5 \mathrm{~km}$ along the fault.

Not all earthquakes can be recorded by a seismic network. Typically, if $70 \%$ of stations detect an event within the same time interval of several seconds, the network is triggered and the event is recorded and located and made available in catalogues. Usually all events above magnitude 1.5 are being recorded. This reveals itself in the statistics of regional seismicity giving a good fit to the Gutenberg-Richter law. However, smaller magnitude events are not all detected due to their low amplitudes relative to the seismic noise. In fact, less then $5 \%$ of all magnitude 0 events are recorded which also defines the regional probability of such event detection. Although the recorded events of magnitude < 1 cannot, therefore, be used for Gutenber-Richter law statistics, they nonetheless can give rise to a strong precursory signature as seen below.

\section{Results}

The USGS catalog was used to analyze the spatial and temporal distribution of events in an approximately $35 \mathrm{~km} \times 50 \mathrm{~km}$ square area around Parkfield from 1965 to the present. To begin, the total number of events occurring per month was computed and analyzed. During this period of observation, four distinct peaks of seismicity are visible in the data. The first three peaks correspond to aftershock series after M5.5 1975 Parkfield, M6.3 1983 Coalinga, and four M4 1993-1994 Parkfield events. The last rise of seismicity starts in 2000, reaches its peak in December 2003 and then falls down below the average level until the M6 2004 event. To eliminate the influence of aftershock and 
creeping seismicity, all seismic events within a $5 \mathrm{~km}$ corridor around the central SAF zone were excluded from the data (as shown in Figure 1). The resulting seismicity is shown in Fig.2a,b. Except for the two sharp peaks in 1970 (M3.9 Parkfield aftershocks) and 1983 (M6.3 Coalinga aftershocks), the only rise in seismicity can be observed starting in the middle of 2002 with a maximum in May 2004. Visible are cyclic bursts of seismicity with decreasing intervals between peaks as time approaches the earthquake.

Further elimination of all events with magnitudes greater than 0.1 gives even more distinctive results (Figure 2c,d). The peak in such "microseimicity" occurs about 4-6 months (March-May 2004) prior to the main M6 2004 event, and is 16 times greater than the background level of roughly one recorded event per month. Following the peak, there is a steady decrease in activity until the time of the main event. Prior to the peak, no distinctive features can be seen in this microseismicity. During the year prior to the main event, the epicenters of the microseismicity are mostly concentrated along the delineation zone between the creeping and locked parts of the SAF (Figure 3). Also during this period, an area approximately $30 \mathrm{~km}$ in diameter surrounding the future M6 2003 epicenter contains no events. This no-activity area lies mostly on the SW side of the SAF. Comparison with borehole dilatometer data (12) shows changes synchronous with AE peaks for the stations DL01 and VC01 (Figure 4), which are located close to high $A E$ zones, whereas other records of other three stations FR01, JC01, RH01 (locations of the stations are shown on Figure 3) do not exhibit pre- M6 event peculiarities.

A similar analysis was applied to the events leading up to the M7.0 1989 Loma Prieta earthquake which caused substantial damage in the San Francisco Bay Area region. The area on the West of the epicenter was chosen for selection of seismicity as it does not contain as many active faults as other areas adjacent to the epicenter. Figure 5 shows seismicity history during 25 years of observation before the event. Two months before the event (Figure 5c,d) the seismicity increased about 8 times compared to the base level of about 6 events per month. Then it decreased during the last two months. Analysis of the low magnitude $(<0.1)$ seismicity gave the same trend, although there were not enough events for statistically significant results. Similar to the Parkfield case, on the last year before the earthquake, a low seismicity area appeared around the future 
rupture (Figure 5b). Existence of this area was shown in (13) after comparing long periods of seismicity before and after the earthquake.

\section{Discussion.}

The out-of-fault-zone microseismicity pattern for both considered events is quite similar, consisting of a sharp seismicity increase that reaches a maximum several months prior to the main event, and then decreases to background seismicity levels at which time the main event occurs. Author proposes an explanation of this behavior understanding that plausible answers should be the results of special studies.

Increase of $A E$ in rocks under increasing stress is a well-known laboratory observation $(14,15,16)$. Under increasing shear strain, the AE of an initially intact rock sample grows throughout the so-called "strain-hardening regime" reaching a maximum after which the $\mathrm{AE}$ rate drops as the rock sample enters the "softening" stage associated with strain localization and failure along a band of accumulated damage $(17,18)$. It is important to note that as usual the constant rate load experiments do not produce visible decrease of $A E$ before the rock failure, while constant stress experiments give such peaks which is supported by laboratory data (19) and by numerical modeling (20). In the presence of pre-existing faults in nature (like the SAF), a slightly different scenario is plausibly imagined. As strain builds through tectonic loading, it appears that at sufficiently large strain, the crust enters a strain-hardening regime in which the crust surrounding the fault begins to microcrack as manifest through the increased level of $A E$ observed, for example, in Fig. 2d. However, as the AE intensifies, and strain continues to build, slip velocities on portions of the fault may begin to increase. Bathing the fault in the vibrations of $\mathrm{AE}$ may change, for example, the rate-and-state parameters (21) controlling the slip rate on the fault $(22,23)$. In particular, the state variable used to characterize the average age of contact asperities in the rate-and-state formalism is likely to be decreased along the fault due to vibrations. Accordingly, the laws of rate-and-state friction (23) predict there will be an increase in slip rate that will both decrease the strain and $A E$ activity in the surrounding crust, as well as decrease the time to which the next high-velocity event (earthquake) will occur. The pre-event seismicity oscillation for the Parkfield earthquake might be caused by seismic activity of the creeping section of SAF due to periodical stress discharge with increasing rate. 
The spatial distribution of the AE at Parkfield is now qualitatively described. Stress must concentrate where the stably sliding (or "creeping") portion of the SAF to the north of Parkfield meets the unstable "locked" portion (though slipping to a very small degree in the rate-and-state description) to the south. This enhanced stress in the crust surrounding the creeping/locked intersection is likely why the AE activity is generally concentrated there. The $30 \mathrm{~km}$ diameter zone surrounding the epicenter that exhibits low seismic activity in the year prior to the main event is more subtle to explain in qualitative terms. Suffice it to say that the rocks to the south-west of SAF where this zone lies contain granite and are generally stronger than the sedimentary rocks to the north-east. Such heterogeneity combined with the intersection of the locked and creeping sections of the SAF will result in complicated local stress patterns. Only numerical simulations will indicate whether the modeled stress concentrations are consistent with the observed spatial distribution of AE. Usually, the fault zones are subjected to a constant strain change rate and have a long history of periodic slip, with repeated maximum stress values and orientations. As a result of such cyclic stress load, most of the used to be overcrically stressed fractures are discharged and application of the same loading conditions does not trigger many of new events. The common assumption considers the rock masses, as containing numerous critically stressed fractures with random locations and orientations. While in the locked parts of the fault zones the stress changes occur primarily along the same directions, in the transition zones stress gradients are high and stress changes lead to changes in orientations of principal stresses. This adds new dimensions for triggering of critically stressed fractures and explains the shown observations of increased seismicity in the transition zones. These arguments are supported by reduction of strain changes rate in Parkfield area which are observed at AE peak time (Figure 4).

For the purpose of pre-earthquake monitoring, four types of seismicity might be considered. First, there is the weak (creeping) fault seismicity, which is a result of steady strain release, that will entirely dominate the percentage of all regional events. Seismicity of this type is not directly related to stress build up in the locked portion of the fault. The second type of seismicity behavior is related to areas around nucleation zones of the future earthquakes, where decrease of seimicity is observed in pre-event stage. Such zones resemble Mogi doughnuts (24) and can have very prolonged shapes approximately equal to the size of the future event rupture zone (13). The third 
seismicity type corresponds to aftershock series of moderate and large events, which might significantly contribute in overall statistics but do not provide obvious clues about large earthquake preparation. The fourth type is the out-off-fault-zone seismicity occurring in the relatively intact surrounding the fault zones. This type of seismicity is directly related to the stress build up in the crust and has only a moderate number of detectable events (since these events are small). The results of this paper were mainly based on this fourth seismicity type. It is speculated here that the shape and size of the region over which this fourth seismicity type is observed to concentrate is directly related to the magnitude of the future main event. The more of the fault that is bathed in the $A E$, the larger will be the area of the fault experiencing accelerated slip with the subsequent possibility of a larger induced earthquake.

Due to the absence of other precursors, the observed pre-event peaks of seismicity reported here are especially important for use in earthquake prediction. The peak's occurrence several months before the event should give opportunity for making special observations of the future rupture zones targeted to accurately estimate the earthquake striking time. Low pre-event seismicity level in these zones require active monitoring using controlled seismic sources in order to observe changes within the fault zone associated with rock softening. It seems natural that rock softening should affect seismic wave attenuation and velocities, although the physics that would allow modeling of such changes is not yet well known.

\section{Conclusions}

Peaks of AE occurring several months before two recent SAF large events indicate that they are good candidates for earthquake prediction studies. Aftershock series and creeping fault seismic activity mask the effect and have been excluded from the data as having little or no relation with stress build up in the locked fault zones. The size and location of the earthquakes under preparation correspond to both the size and location of both the "quiet" zones and the zones of increased $A E$. Because of their frequent occurrence, small magnitude events might be ideal for routine daily monitoring of stress changes. Development of active seismic monitoring techniques are necessary for investigating changes in the pre-seismic nucleation zone. The observations reported here leave open the hope that earthquake prediction may yet be possible. 


\section{Acknowledgments}

Data processing was done at the Center for Computational Seismology (CCS) at Lawrence Berkeley National Laboratory, which is operated by the University of California for the U.S. Department of Energy (DOE) under contract No. DE-AC03-76SF00098. Author thanks Federica Marone for supplying earthquake data. Robert Nadeau made several helpful comments. This paper significantly benefited from the help and suggestions of Steven Pride.

\section{REFERENCES}

[1] Bakun, W.H. and A.G. Lindh, The Parkfield, California, prediction experiment, Earthq. Predict. Res., 3,285-304, 1985.

[2] Langbein, J., Borherdt, R., Dreger, D., Fletcher, J., Hardebeck, J.L., Hellweg, M., Ji, C., Johnston, M., Murray, J.R., Nadeau, R.N., Rymer, M. J., Treiman, J.A., Preliminary report on the 29 September 2004, M 6.0 Park field, California earthquake, 2004, Submitted to SRL

[3] Geller, R.J. Earthquake prediction: a critical review. Geophys. J. Int. 131, 425-450 (1997).

[4] http://earthquake.usgs.gov/hazards/prediction.html

[5] Robert J. Geller, David D. Jackson, Yan Y. Kagan, Francesco Mulargia , 1996, Earthquakes cannot be predicted. Science, Vol. 275, n. 5306, pp. 1616 [6] http://www.nature.com/nature/debates/earthquake/index.html [7] Bowman, D. D. and C. G. Sammis, Intermittent criticality and the Gutenberg-Richter distribution, Pure Appl. Geophys., 104, 1945-1956, doi:10.1007/s00024-004-2541-z, 2004.

[8] Karageorgi, E., R. Clymer and T.V. McEvilly, Seismological studies at Parkfield: II. Search for temporalvariations in wave propagation using Vibroseis, Bull. Seismol. Soc. Am., 82, 1388-1415, 1992.

[9] Karageorgi, E.D., T.V. McEvilly, and R.W. Clymer, Seismological studies at Parkfield IV: Variations incontrolled-source waveform parameters and their correlation with seismic activity 1987-1994, Bull.Seism. Soc. Am., 1996.

[10] Korneev, V.A., T.V. McEvilly, and E.D. Karageorgi, Seismological studies at Parkfield VIII: Modeling theobserved travel-time changes, Bull. Seismol. Soc. Am., 90 (3), 702-708, 2000. 
[11] Korneev, V. A., Nadeau, , R. M. and T. V. McEvilly, 2003, Seismological Studies at Parkfield IX: Fault Zone Imaging using Guided Wave Attenuation, Bull. Seism. Soc.

Am., vol.93,\#4, 1415-1426.

[12] http://quake.wr.usgs.gov/research/deformation/monitoring/pk.html

[13] Reasenberg, P.A. and R.W. Simpson, 1992, Response of regional seismicity to the static stress change by the Loma Prieta earthquake, Vol 255, pp. 1687-1690.

[14] Lei, X.-L., K. Kusunose, O. Nishizawa, A. Cho, and T. Satoh, On the Spatiotemporal Distribution of Acoustic Emissions in Two Granitic Rocks Under Triaxial Compression: the Role of Pre-existing Cracks, Geophys. Res. Lett. Vol. 27 , No. 13 , p.1997-2000, 2000.

[15] Lei, X.-L., K. Kusunose, M.V.M.S. Rao, O. Nishizawa, and T. Satoh, Quasi-static fault growth and cracking in homogeneous brittle rocks under triaxial compression using acoustic emission monitoring, J. Geophys. Res., Vol.105, No.B3 , p.6127-6139, 2000.

[16] Lockner, D. A., J. Byerlee, V. Kusenko, A. Ponomareve, and A. Sidorin, Observations of quasistatic fault growth from acoustic emissions, in Fault Mechanics and Transport Properties of Rocks, edited by B. Evans and T.-F Wong, pp. 3-31, Academic Press, London, 1992.

[17] Lei, X.-L., K. Masuda, O. Nishizawa, L. Jouniaux, L. Liu, W. Ma, T. Satoh, K. Kusunose, Detailed analysis of acoustic emission activity during catastrophic fracture of faults in rocks, J. Struct. Geol., 26, 247-258, 2004.

[18] Sobolev, G.A., Babichev, O.V., Los,V.F., Kol'tsov,A.V., Ponomaryov,A.V., Ponyatovskaya, V.I., Rozanov, A.S., Stanchits, S.A., Khromov, A.A., Frolov, D.I., Yangquan,L., Jialiu,Z., Jiadong, Q. and L. Shiyu, 1996, Precursors of the destruction of water containing blocks of rock., J. Earthquake Prediction Research,

[19] Lei, X.-L. , T. Satoh, O. Nishizawa, K. Kusunose, M.V.M.S. Rao, Modeling Damage Creation in Stressed Brittle Rocks by Means of Acoustic Emission, Proceedings of the Sixth International Symposium on Rockburst and Seismicity in Mines (RaSiM6), , In print http://staff.aist.go.jp/xinglinlei/Publication/Papers/Papers.htm

[20] Tham, L. G., Cheung, Y. K. and C. A. Tang, Numerical Simulation of the Failure Process of Rocks, Tamkang Journal of Science and Engineering, Vol. 4, No. 4, pp. 239252 (2001) 239 
[21] H. J. Melosh. Acoustic fluidization: A new geologic process? JGR, 84:7513-7520, 1979.

[22] Ruina, A. L. Slip instability and state variable-friction laws, J. Geophys. Res., 88, 10359-10370, 1983.

[23] Dietrich, J. A., A constitutive law for rate of earthquake production and its application to earthquake clustering, J. Geophys. Res., 99, 2601-2618, 1994. [24] Mogi, K., 1985. Earthquake Prediction. Academic Press, Tokyo.

Valeri Korneev,

90-1116, ESD, 1 Cyclotron Rd, Lawrence

Berkeley National Laboratory, Berkeley, CA

94720, USA;: VAKorneev@lbl.gov 


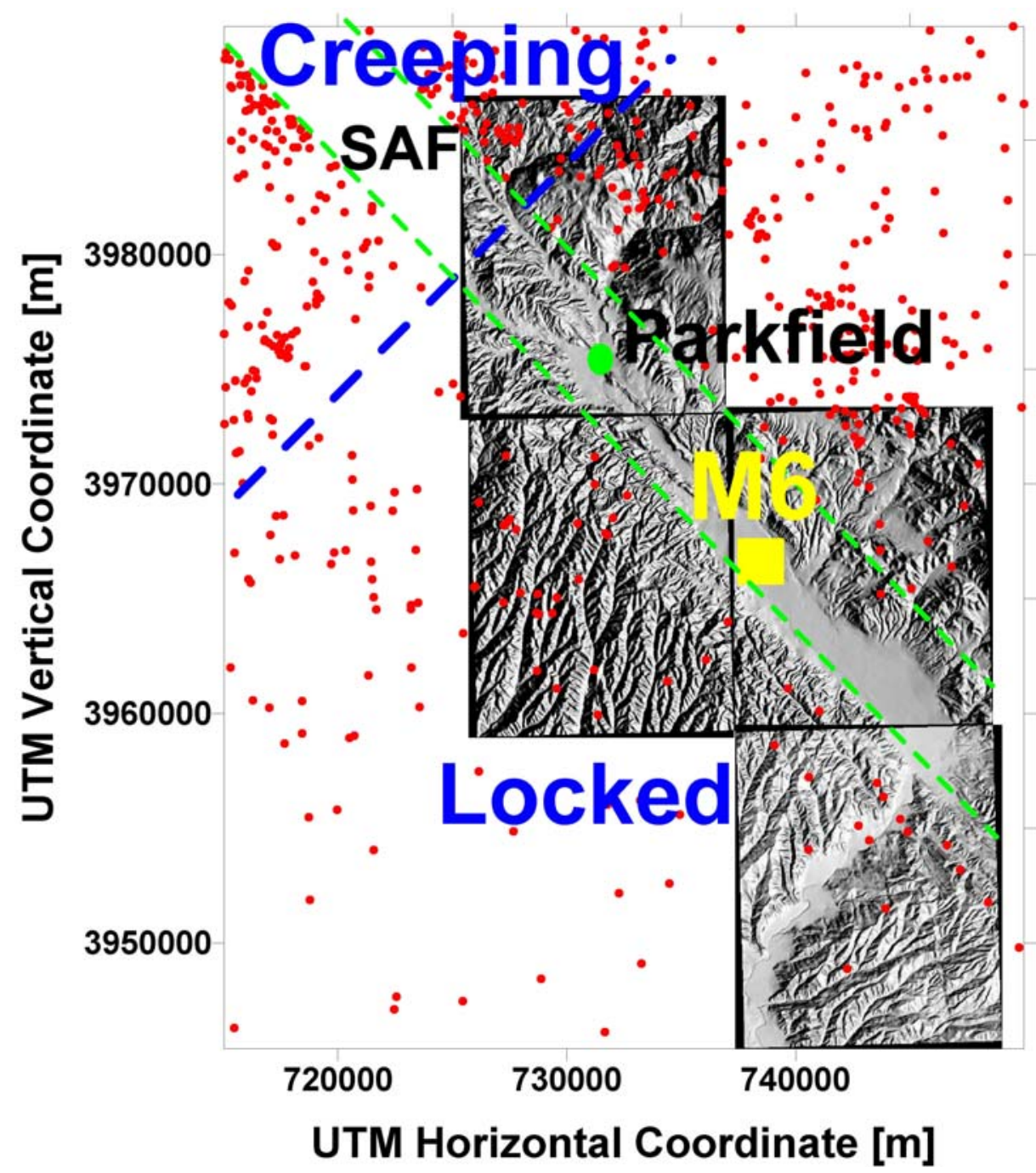

Figure 1. Seismicity of SAF at Parkfield area during 35 years before M6.0 September 28, 2004 earthquake. Fault zone events within $5 \mathrm{~km}$ corridor around the SAF trace are excluded. Partially shown the topographic map of Parkfield area. Red dots are the event epicenters. Dashed green lines are the bounds of excluded corridor around SAF. Dashed blue line is delineation zone (Korneev et al. 2003) between locked and creeping parts of SAF. Yellow square marks the epicenter of M6.0 event. 
(a)

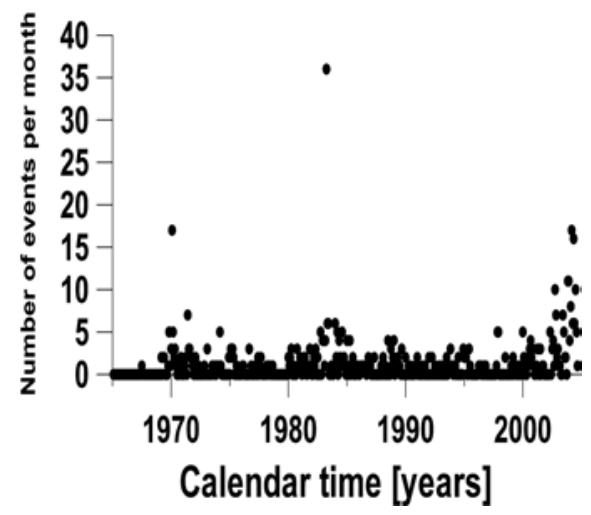

(b)

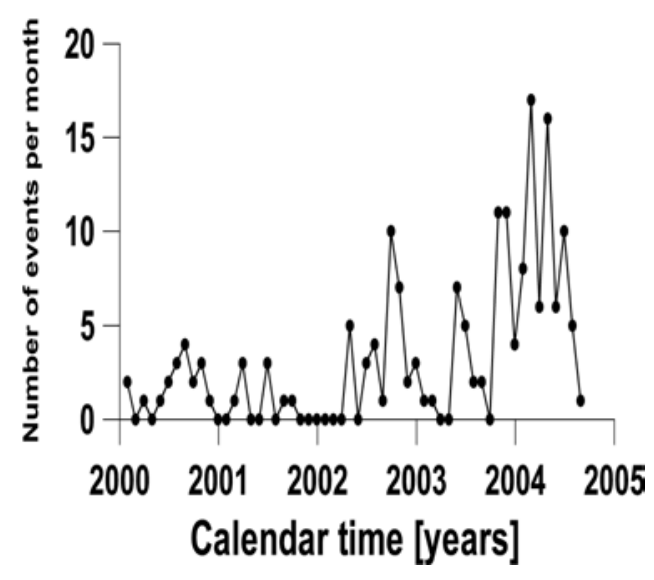

(c)

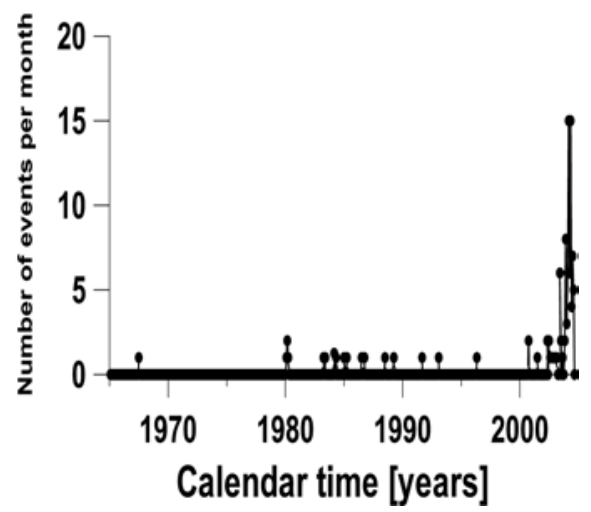

(d)

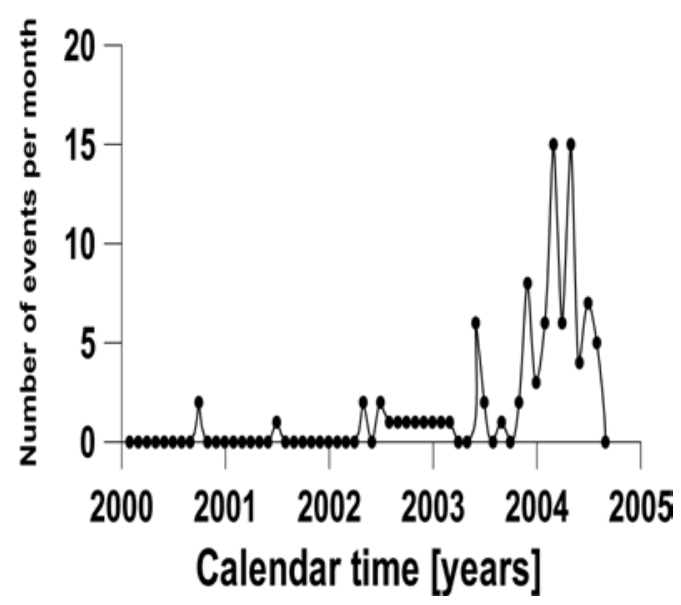

Figure 2. Average number of events per mont at Parkfield area before M6.0 September 28, 2004 earthquake. (a) All events starting from 1967. The 1970 and 1983 spikes are correspondently post seismic aftershocks of M4 SAF and M6.3 Coalinga events. (b) Same as on (a) starting from 2000. Visible are cyclic bursts of seismicity with decreasing intervals between peaks as time approaches the earthquake. (c) Small $(M<0.1)$ magnitude events of the same series as on $a)$. The only sharp increase in seismicity starts a year before the main event. (d) Same as on (c) starting from 2000. The seismicity peak is reached $4-6$ months before the earthquake followed by steady decrease. 




Figure 3. Seismicity of SAF at Parkfield area during 1 year before M6.0 September 28, 2004 earthquake. Fault zone events within $5 \mathrm{~km}$ corridor around the SAF trace are excluded. Partially shown the topographic map of Parkfield area. Red dots are the event epicenters. Dashed green lines are the bounds of excluded corridor around SAF. Dashed blue line is delineation zone between locked and creeping parts of SAF. Yellow square marks the epicenter of M6.0 event. Black diamonds show positions of dilatometer strainmeters. 
(a)

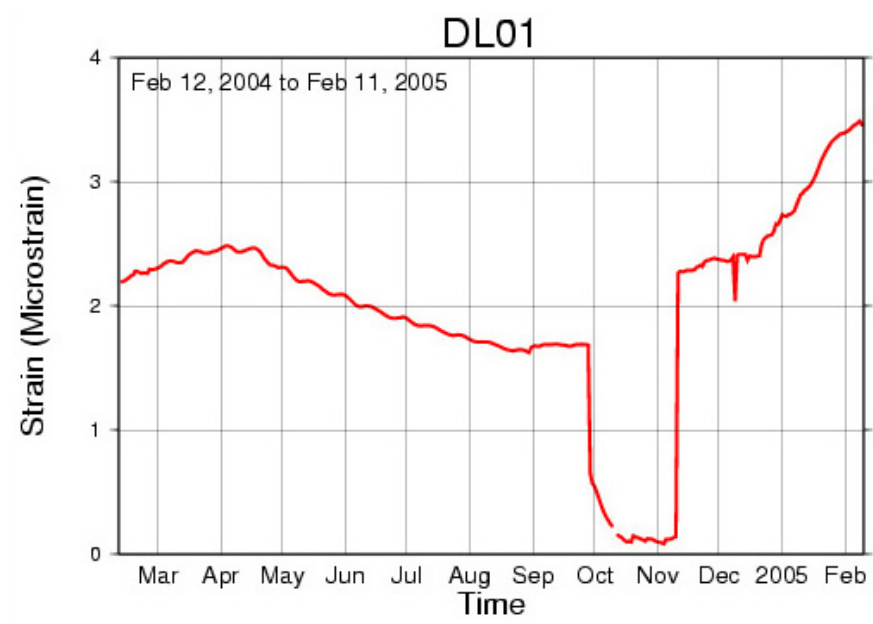

(b)

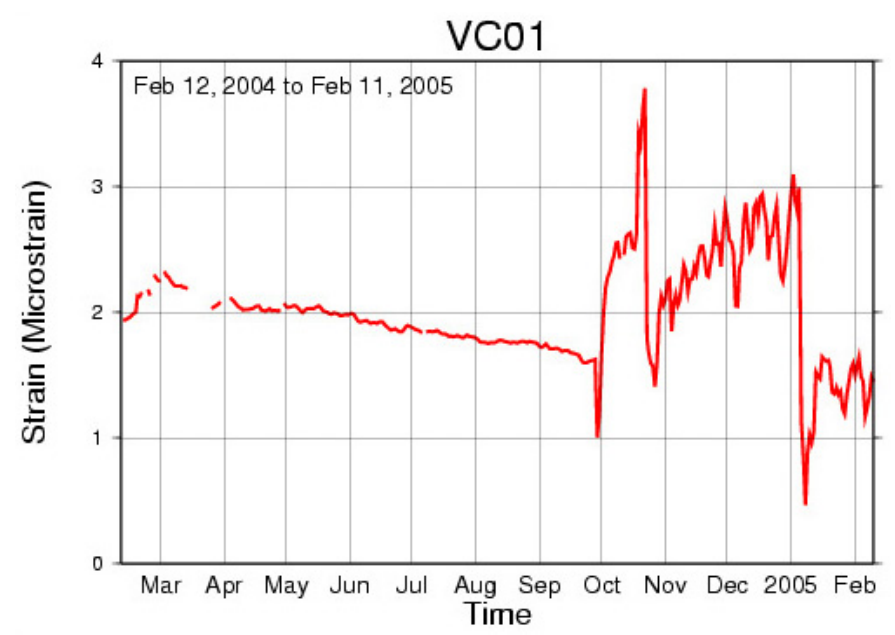

Figure 4. Borehole dilatometers reacords for Park field area. Stations DL01 (a) and VC01 (b) are located close to high AE zones and recorded pre event schanges in March-April 2004 that corresponds to AE peak time. Records from other stations (see Figure 3) do not have such changes (). 
(a)

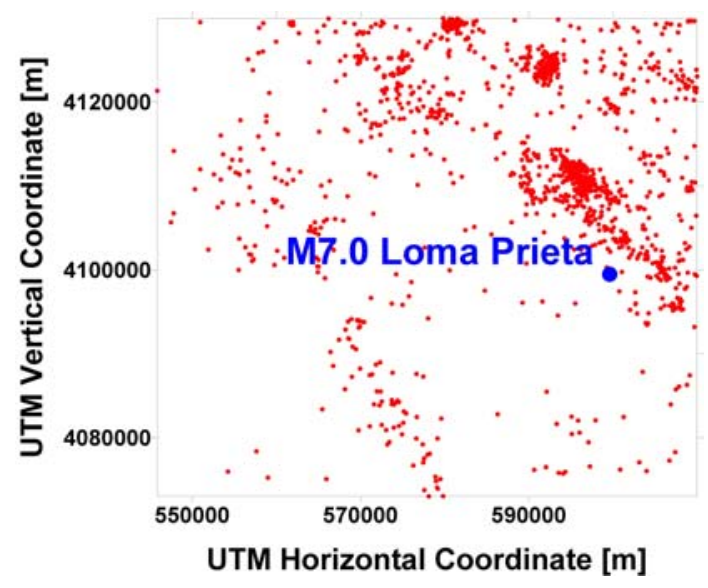

(c)

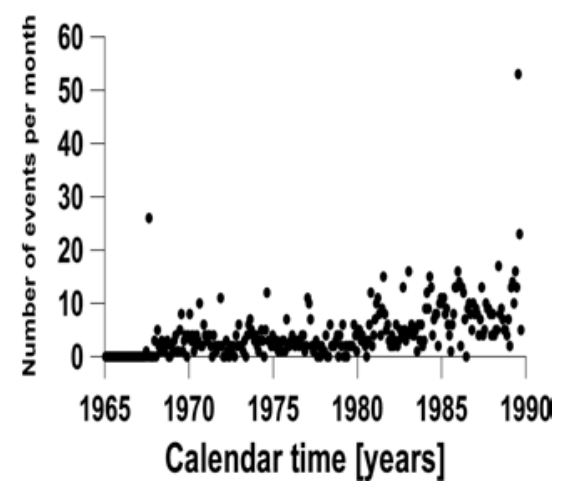

(b)

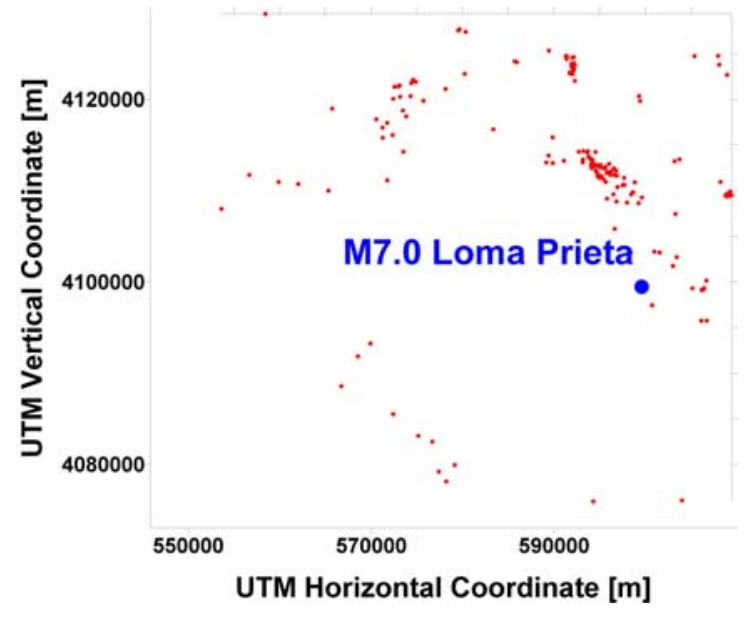

(d)

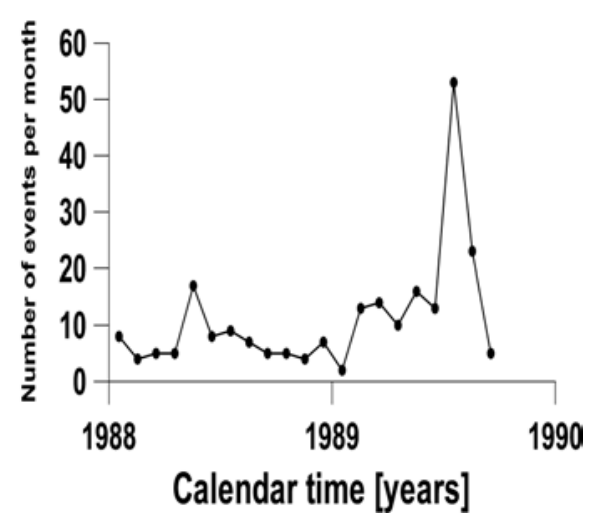

Figure 5. Seismicity of SAF at westernly Loma Prieta area before M7.0 October 15 earthquake. a) Red dots are the event epicenters. b) Same as on previous panel when just the events of the last year are plotted. Note the "quiet" zone on southwest of the SAF, which is similar to that on Figure 1b. c) Average number of earthquakes per month starting from 1966. d) Same as on c) starting from 1988. The seismicity peak is reached 2 months before the earthquake followed by steady decrease. 